\title{
Occurrence of suppurative lymphadenitis after a change of BCG vaccine
}

\author{
Department of \\ Paediatric Surgery, \\ University Hospital \\ Innsbruck \\ Paul Hengster \\ Jörg Schnapka \\ Gesine Menardi \\ Institute for Hygiene, \\ Innsbruck \\ Manfred Fille \\ Correspondence to: \\ Dr Paul Hengster, \\ Department of \\ Paediatric Surgery, \\ University Hospital \\ Innsbruck, \\ Anichstrasse 35, \\ A-6020 Innsbruck, \\ Austria. \\ Accepted 4 February 1992
}

\author{
Paul Hengster, Jörg Schnapka, Manfred Fille, Gesine Menardi
}

\begin{abstract}
BCG vaccines are the oldest vaccines in use today, but the protective effect of the vaccination is still controversial. The risk of contracting tuberculosis is low compared with the possible complications after this vaccination. In Austria the formerly used BCG vaccine was not available in the required amount and another vaccine was released by the drug authorities. This product, with a more virulent strain, was used between August and December 1990, and this increased the incidence of complications. Eighty four of 1950 vaccinated newborn babies developed severe suppurative lymphadenitis three to 28 weeks after the vaccination, and surgical treatment was found to be necessary. Isoniazid treatment did not prove to be successful when the lymph node exceeded a certain size. Culture was successful in $46 \%$ up to week 20; after 20 weeks no culture became positive. All cultured bacteria were isoniazid sensitive.

The question of general vaccination is raised and several points were considered before we came to the conclusion that except for high risk groups a general vaccination programme for neonates is not justified in Western countries.
\end{abstract}

BCG (Bacille Calmette-Guérin) vaccines are the oldest vaccines in use today. They were derived in 1906 by in vitro attenuation and, after 230 in vitro culture passages by Calmette and Guérin, were first used as oral vaccines in 1921. The subcutaneous application used at the present time was introduced by Wallgren in 1927.

After vaccination a positive tine test has been reported in $44 \%$ to $84 \%$ of cases and an even higher percentage $(98 \%)$ reported for the Mantoux test two years after vaccination. ${ }^{12}$ The protective effect of the BCG vaccination has been estimated in many studies to be between 0 and $80 \%$; in infants it seems to lie around $60 \%$, based on known contacts of persons with confirmed tuberculosis. ${ }^{3-5}$ Recently the preventive impact of BCG vaccination has been shown by reports of high risks of tuberculosis in infants-in Egypt $76.7 \%$ and in Togo $64.5 \%$ - who had not been vaccinated. ${ }^{4} 6$ The protective effect of vaccination wanes significantly after the age of about 5 years. ${ }^{147}$

In 1952 the Ministry of Health in Austria, as in many other countries except for the USA and the Netherlands, both of which never used it on a national scale, recommended a general vaccination of newborn infants as a preventive measure against tuberculosis. In Germany the vaccination of the newborn was stopped due to complications in 1976. In Austria the risk of contact with tubercular bacilli during infancy is low (the incidence of reported cases in the whole population is less than $0.05 \%$ ) except in diseased families. ${ }^{8}$ Complications with BCG vaccines, such as suppurative lymphadenitis, osteitis, or even generalised tuberculosis, were reported in $0 \cdot 01-3 \cdot 8 \%$ even with the earlier strain. Nevertheless, in our hospital we had not performed any operation for suppurative lymphadenitis since $1974 .^{9} 10$

Taking into account the low risk of acquiring tuberculosis $(0.03 \%)$ and the incidence of severe complications from using the vaccine, the recommendation in Austria in 1989 changed to vaccination of high risk groups only: those in slum districts, refugee quarters, or endemic areas, children of diseased families, or of parents working in danger zones such as certain hospitals. ${ }^{11}$ Nevertheless, many paediatricians did not change their views and continued with general vaccination.

Based on the false assumption that paediatricians were following the health authorities, recommendation, BCG Berna (strain Kopenhagen) was not stored in a sufficient amount. The vaccine BCG-Pasteur Intradermal $P$, Charge $R$ 5520, was released by the Austrian drug authorities and the usual demanding licencing procedures were dropped. However, this product contains a much more virulent strain of the tubercle bacillus. It was already known by the World Health Organisation (WHO) to produce a higher rate of complications, ${ }^{12}$ and for this reason the vaccine had been replaced. The Pasteur vaccine was used in some hospitals in the dosage of about $0.05 \mathrm{ml}$ intradermally from the beginning of August to December 1990 until its use was prohibited by the Ministry of Health on the 28 November as a result of the alarming reports of a sudden increase in the occurrence of suppurative lymphadenitis.

The known fact led to the conclusion that the new vaccine raised the incidence of complications-a suspicion we initially expressed in a preliminary report. ${ }^{13}$

\section{Subjects and methods}

The department of paediatric surgery of the University Hospital Innsbruck is the only centre for paediatric surgery in the Tyrol, an area with about 500000 inhabitants. In the critical period from August to December 1990, 3386 children were born and 1950 of these were vaccinated with the Pasteur vaccine. This is documented 
by the authorities responsible for public health in the country. The dosage used was $0.05 \mathrm{ml}$, but in intracutaneous application the real amount is not exactly determined, because a small amount of the vaccine flows back due to the high intracutaneous pressure.

All children in this area were admitted to our hospital if surgical treatment was found necessary. The indication for surgical treatment was a fluctuating lymph node exceeding $1 \mathrm{~cm}$ in diameter, the inflammation infiltrating the surrounding skin, or spontaneous perforation or fistula. Under general anaesthesia an excision and excochleation of the necrotic tissue was performed. The material was sent to the Institute for Bacteriology where culture was developed on Löwenstein Jensen agar. ${ }^{14}$

\section{Results}

All 1950 newborn babies were mature except for one who was born in the 37th gestational week. The mean (SD) birth weight was $3500(480) \mathrm{g}$. From November until 10 June, 84 of these children developed symptoms and were admitted for surgical treatment. The time between vaccination and surgery was surprisingly long. Suppurative lymphadenitis occurred within three to 28 weeks with a mean of 13.8 weeks (fig 1).

At the time they underwent surgery $34.5 \%$ of the infants had been on isoniazid treatment for one to 12 weeks already. Localised lymphadenitis was present in $\mathbf{4 4}$ boys and $\mathbf{4 0}$ girls: its distribution was axillary $(59 \cdot 5 \%)$, supraclavicular $(29 \cdot 7 \%)$, nuchal $(3 \cdot 6 \%)$, cervical $(3 \cdot 6 \%)$, scapular $(2 \cdot 4 \%)$, and on the upper arm $(1 \cdot 2 \%)$. In $92.9 \%$ it was unilocular, and $7 \cdot 1 \%$ had more than one enlarged lymph node at a different location. The size ranged from 1 to $4 \mathrm{~cm}$ in diameter. The area was typically reddened and in $4.7 \%$ spontaneous perforation occurred (figs $2-4)$. In $92.9 \%$ one operation, in $5.9 \%$ two, and in $1.2 \%$ three repeated operations were necessary due to further occurrence to lymphadenitis in another location.

In these infants the suppurative lymph nodes were totally removed surgically and showed caseous necrosis after incision. The excised necrotic tissue was sent to the Institute for

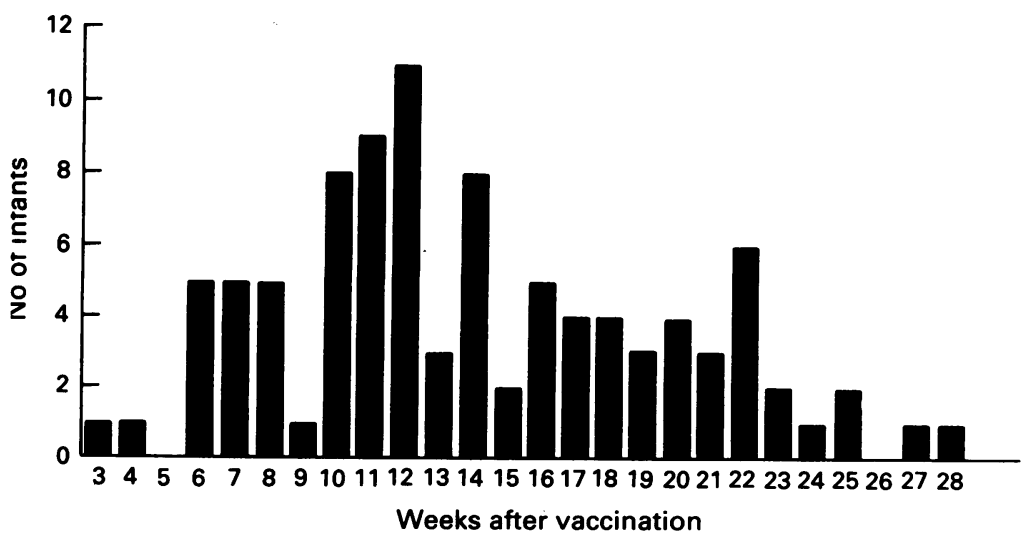

Figure 1 Suppurative lymphadenitis in newborn infants showing the time of surgery in eaction to vaccination (University Hospital Innsbruck).

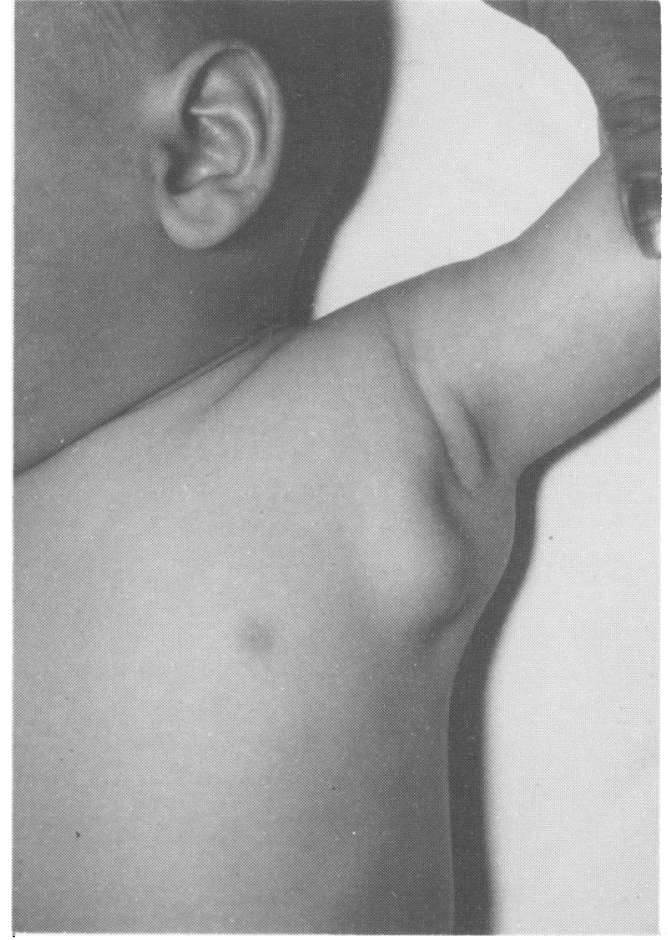

Figure 2 Lymphadenitis 10 weeks after vaccination.

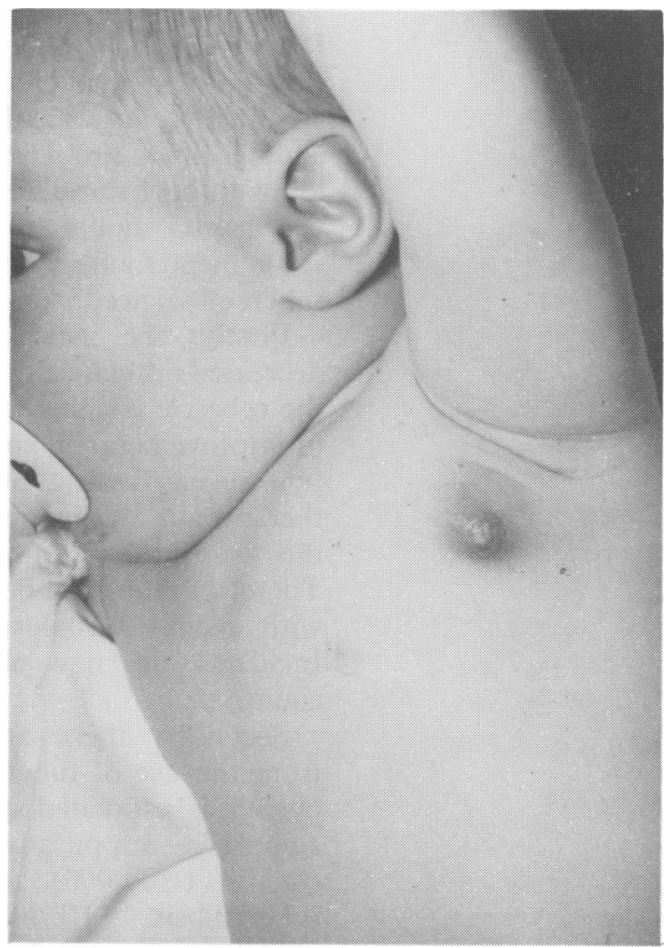

Figure 3 Lymphadenitis 12 weeks after vaccination, with infiltration of the skin.

Bacteriology for culture. On Löwenstein Jensen agar cultural detection of tubercle bacilli was successful in $46 \%$ up to week 20 after vaccination. After 20 weeks no culture became positive. All cultured bacteria were isoniazid sensitive.

All children were treated with isoniazid $10 \mathrm{mg} / \mathrm{kg}$ body weight plus $10 \mathrm{mg}$ vitamin B-6 (Benadon, Roche) daily for six weeks. 


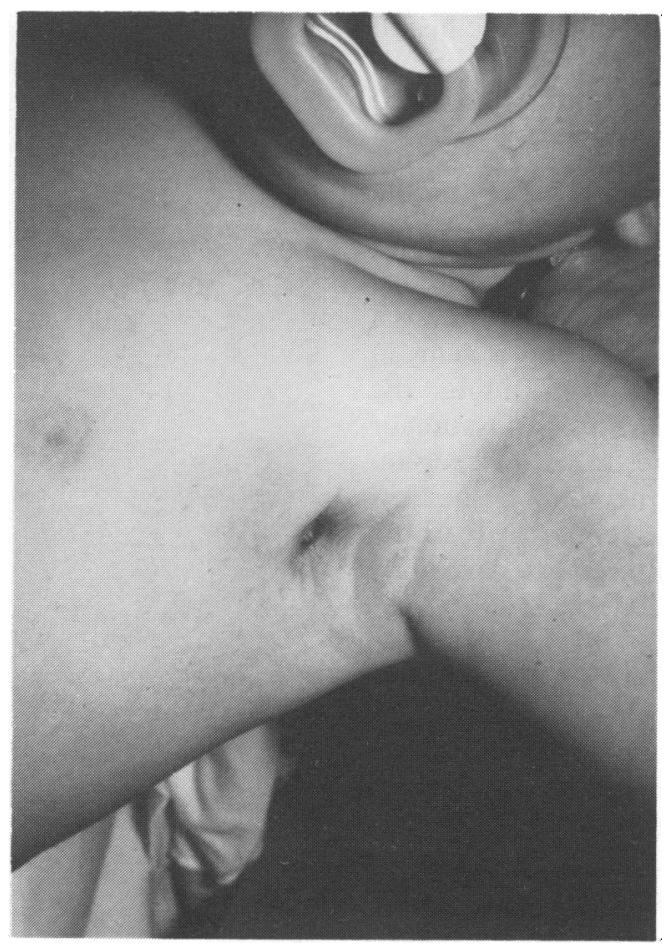

Figure 4 Lymphadenitis 13 weeks after vaccination, with spontaneous perforation.

\section{Discussion}

Infection from tuberculosis is rare in neonates and infants, but when it happens it is dangerous and means a prolonged morbidity despite all known therapeutic measures. In principle, a vaccination should solve these problems but a recommendation for general vaccination against tuberculosis needs some consideration.

Firstly, the incidence of tuberculosis has decreased dramatically. This started even before the tubercle bacillus was detected and was due to improvements in social standards and nutrition during the last 100 years. Neither chemotherapy nor vaccination alone have influenced this drop in cases of tuberculosis significantly. Therefore the number of infectious persons with open tuberculosis had declined. ${ }^{8} 11$ 15 16 Incidence lies now about $0.03 \%$ in Western countries.

Secondly, there are complications arising from the use of tubercular vaccines. The rate overall is estimated at about $0.01 \%$ to $3.6 \%$ comprising suppurative lymphadenitis (1/100), osteitis $(1 / 100000)$, and even fatal generalised tuberculosis (1/1000 000). ${ }^{2} 17-19$ Reported complication rates depended on the dosage of vaccine used being $0.68 \%$ and $0.09 \%$ respectively for $2 \times 10^{5}$ and $0.5 \times 10^{5}$ viable units of the Pasteur vaccine. ${ }^{18}$ In striking contrast is our rate of severe complication with $1 \times 10^{5}$ viable units of this vaccine, making surgical treatment necessary in $4.5 \%$. One report showed the nonsuppurative lymphadenitis to occur in $18 \%$ of children vaccinated with a Pasteur vaccine. ${ }^{20}$

Thirdly, the protection rate was supposed to be $80 \%$ for a duration of about 15 years, an opinion based on positive tine or Mantoux tests. However, there are reports on the waning effectiveness of vaccination after the age of 5 years. Even if in non-vaccinated children the rate of infection is higher than in vaccinated ones it is not acceptable to compare these two groups by randomised studies only without taking the social and nutritional status into account. ${ }^{1521}$ The most reliable report is a casecontrol study ${ }^{22}$ showing a protection rate of $64 \%$.

Fourthly, vaccination means a loss of the diagnostic value of intracutaneous tests (tine, Mantoux), which only show a positive reaction due to vaccination and not to 'wild type' infection.

Statistically, a life span of 100 years carries the same risk of acquiring tuberculosis as of suffering severe side effects due to vaccination. Even with vaccination there is no guarantee of total protection; the possibility of increased resistance has never been confirmed. Furthermore, no positive effect of vaccination in reducing the death rate can be shown; since 1970 no child (0-14 years) living in our area had died from tuberculosis. The tine test of Mantoux test is no proof of protection, it shows only that contact with bacilli has taken place.

After taking all these facts into consideration we must come to the conclusion that a general vaccination programme for neonates lacks justification. The WHO and also the Austrian health authorities met these deliberations with their recommendation to stop general vaccination in neonates except in 'high risk groups'.

In Austria, when the BCG vaccine was replaced by another product, the Pasteur vaccine, which uses a different strain of the bacillus, none of the usual licensing procedures were enforced. Also, each strain of bacillus reacts differently, and these strains cannot be compared directly with each other. ${ }^{12} 2023$ It would appear that neither the producer nor licenser was aware of reports concerning the increased complication rate of the new vaccine. They allowed the production and commercial distribution of the product. This raises the question of the value of control procedures performed by or for a company. Also the actions of the licencing institution in allowing the commercial distribution of the vaccine cause concern.

The site of lymphadenitis in the supraclavicular, nuchal, and even cervical region must be attributed to a wrong application point. Paediatricians seem not to be aware of vaccinating at a point slightly above the recommended location - that is over the insertion of the deltoid muscle.

The complication rate reported by us refers only to severe cases, which were all sent to our centre. The overall complication rate is even higher, as this included cases with less severe lymphadenitis where the conservative approach may have been successful.

Some patients had already had isoniazid treatment before surgery. Although all tubercle bacilli were isoniazid sensitive, the inflammatory process proceeded when the lymph node had reached a certain size. The failure of conservative measures clearly showed that surgical excision is the treatment of choice in fluctuant, enlarged lymph nodes or when they have infiltrated the skin. ${ }^{24}$ 
The consequences of this occurrence, which raised hysterical reports and discussions in the press and led to a considerable financial burden for Austria, should result in preventive measures to keep the standards of medical services at a high level in the true sense of primum non nocere.

1 Bollag U, Bollag-Albrecht E. Tuberculin reaction and the extent of the vaccination scar following BCG vaccination in
newborn infants. Schweiz Med Wochenschr 1988;118: newborn

2 Stephen U, Haupt H, Scheier R, Nada A, Grimrath U, Schmitt HG. BCG vaccination of the newborn infant with the 131 Copenhagen strain. Klin Padiatr 1986;198:295-8.

3 Paul E, Fine M. The BCG story: lessons from the past and implications for the future. Rev Infect Dis 1989;11:353-9.

4 Tidjani O, Amedome A, Dam HG. The protective effect of BCG vaccination of the newborn against childhood tuber culosis in an African community. Tubercle 1986;67:269-81.

5 Young TK, Hershfield ES. A case-control study to evaluate the effectiveness of mass neonatal BCG vaccination among Canadian Indians. Am $\mathcal{F}$ Public Health 1986;76:783-6.

6 Mahmoud ME, Monhim A. Evaluation of BCG vaccination in Bab El Shaaria zone-Cairo. Dev Biol Stand 1986;58:249-56.

7 Myint TT, Win H, Aye HH, Kyaw-Mint TO. Case-control study on evaluation of BCG vaccination of newborn in study on evaluation of BCG vaccination of newborn

8 Breunig B. BCG Impfung und Kindertuberkulose. Mitteilungen der Oesterreichischen Sanitaetsverwaltung 1990;90: lungen

9 Brehmer W, Falkenberg N, Hussels H, Otto HS, Preulr H, Waldschmidt J. Regionale suppurative Lymphadenitis nach BCG Impfung. Disch Med Wochenschr 1977;35: 1251-5.

10 Milstien JB, Gibson JJ. Quality control of BCG vaccine by WHO: a review of factors that may influence vaccine effectiveness and safety. Bull WHO 1990;58:93-108.
11 Junker E. BCG-Imptung aus heutiger Sicht. Mittetlungen der Oesterreichischen Sanitaetsverwaltung 1990;91:305-9.

12 Lymphadenitis associated with BCG immunization. Wkly Epidemiol Rec 1988;50:381-3.

13 Hengster P, Fille M, Menardi G. Suppurative lymphadenitis in newborn babies after change in BCG vaccine. Lancet 1991;337:1168-9.

14 Fille M, Allerberger F, Hengster P, Pastner E, Menardi G, Dierich MP. Nebenwirkungsrate der BCG-Pasteur Intradermal P Vakzine. Zentralbl Bakteriol Hyg 1992 (in press).

15 Epstein PR. BCG vaccination and nutrition. Lancet 1990;335: 1536-7.

16 McKeown T. Medizinische Errungenschaften. The role of medicine: dream, mirage or nemesis? Frankfurt: Suhrkamp Verlag, 1979:135-61.

17 Hanimann B, Morger R, Barlocher K, Brunner C, Giger T Schopfer K. BCG osteitis in Switzerland: a report of 6 cases. Schweiz Med Wochenschr 1987;117:193-8.

18 Nyerges G, Drinoczy M. Significance of the number of viable units in BCG vaccines. Dev Biol Stand 1986;58:331-6.

19 Moreno L, Gottrand F, Herbaux B, Savage C, Ferriaux JP. Vertebral osteitis following BCG vaccination in a previously healthy child. Eur f Pediatr 1990;149:668-8.

20 Lallemanz-Le Coeur S, Cheynier D, Nzingoula S, Drucker J, Larouze B. Bacillus Calmette-Guérin immunization in infants born to HIV-1-seropositive mothers. AIDS 1991;5: 195-9.

21 Romanas V, Tuberculosis in Bacillus Calmette-Guérin immunized and unimmunized children in Sweden. Pediatr Infect Dis f 1987;6:272-80.

22 Packe GE, Inne JA. Protective effect of BCG vaccination in infant Asians: a case-control study. Arch Dis Child 1988;63: 277-81.

23 Teulieres L, Dioul MA, Chaud P, Saint-Cyr A, Saliou P. Comparative trial of administration of half $(0.05 \mathrm{mg})$ and quarter (0.025 mg) dose of intradermal Pasteur BCG on 291 quarter $(0.025 \mathrm{mg})$ dose of intradermal Pasteur BCG on 291
infants from birth to 1 year in French Guyana. Vaccine infants from birt $1991 ; 9: 521-4$.

24 Caglayan S, Yegin O, Kayran K, Timocin N, Kasirga E, Gun $M$. Is medical therapy effective for regional lymphadenitis following BCG vaccination? Am f D Dis Child 1987 141:1213-4. 